\title{
Altered Expression of PRKX, WNT3 and WNT16 in Human Nodular Basal Cell Carcinoma
}

\author{
NATALIA GURGEL DO CARMO ${ }^{1,2}$, LUIS HENRIQUE TOSHIHIRO SAKAMOTO ${ }^{3}$, \\ ROBERT POGUE $^{1}$, CINTIA DO COUTO MASCARENHAS ${ }^{1}$, SIMONE KARST PASSOS ${ }^{4}$, \\ MARIA SUELI SOARES FELIPE ${ }^{1,2}$ and ROSÂNGELA VIEIRA DE ANDRADE ${ }^{1}$ \\ ${ }^{1}$ Program of Genomic Sciences and Biotechnology, Catholic University of Brasília, Brasília, DF, Brazil; \\ ${ }^{2}$ Program of Molecular Pathology, University of Brasília, Brasília, DF, Brazil; \\ ${ }^{3}$ Domingos A. Boldrini Center for Hematological Investigation, Campinas, SP, Brazil; \\ ${ }^{4}$ Dermatology Service, Asa Norte Regional Hospital, Brasília, DF, Brazil
}

\begin{abstract}
Background/Aim: Nodular and superficial are the most common subtypes of basal cell carcinoma (BCC). Signaling pathways such as Hedgehog $(\mathrm{HH})$ and Wingless (WNT) signaling are associated with BCC phenotypic variation. The aim of the study was to evaluate of the expression profiles of 84 genes related to the WNT and $H H$ signaling pathways in patients with nodular and superficial BCC. Materials and Methods: A total of 58 BCCs and 13 samples of normal skin were evaluated by quantitative realtime polymerase chain reaction $(q P C R)$ to detect the geneexpression profile. Results: qPCR array showed segregation in BCC subtypes compared to healthy skin. PRKX, WNT3 and WNT16 were significantly $(p<0.05)$ altered: PRKX was up-regulated, and WNT3 and WNT16 were down-regulated in nodular BCC. Conclusion: PRKX, WNT3 and WNT16 genes, belonging to the WNT signaling pathway, are involved in the tumorigenic process of nodular BCC.
\end{abstract}

Basal cell carcinoma (BCC) is a common skin tumor in humans (1). It presents slow growth and if left untreated can be locally destructive (2-4). It does not have a high mortality rate, although it is responsible for substantial morbidity, imposing a growing burden on healthcare services $(4,5)$. Significant biological BCC subtypes are nodular, superficial, infiltrative, sclerodermiform, micronodular and mixed BCC forms $(4,6,7)$. Histological BCC subtypes may display

Correspondence to: Rosângela Vieira de Andrade, Ph.D., SGAN 916, Módulo B, Universidade Católica de Brasília (UCB) - Campus II, Bloco C, $2^{\circ}$ andar, Sala - 217, Bairro: Asa Norte, CEP 70790160, Brasília, DF, Brazil. Tel: +55 6134487268, Fax: +55 6133474797, e-mail: rosangelavand@gmail.com

Key Words: Basal cell carcinoma, WNT, Hedgehog, differential gene expression. differences in their biological behavior, such as tumor growth pattern, potential for recurrence and metastasis, histological pattern and genetic factors. In addition, it is important to consider extrinsic factors, such as site of origin, therapeutic choice and immunological state of the person with the tumor (3). Nodular BCC is the most common biopsied subtype; it usually manifests as a single lesion and mostly affects head and neck areas (8). Histologically, the tumor is a well-defined structure with precise contours; it presents basaloid cells of nodular mass separated from the dermis by a typical artefact of separation (8-10). Superficial BCC can be seen as multiple lesions. It is the second most common biopsied subtype, affecting mostly the trunk and shoulder areas. It is seen as a tumoral focus, which goes from the epidermis to papillary dermis, showing peripheral refraction around the tumor $(8,9)$.

The wingless (WNT), hedgehog (HH), epidermal growth factor (EGF), fibroblast growth factor (FGF), insulin-like growth factor (IGF) and transforming growth factor beta (TGF $\beta$ ) signaling pathways are related to development mechanism of skin stem cells (11). WNT and HH have gained notorious attention in skin cancer, especially in BCC. The $\mathrm{HH}$ signaling pathway is known to be activated in most BCCs and mutations in $\mathrm{HH}$ genes, especially Patched 1 (PTCHI) and Smoothened, frizzled class receptor $(S M O)$, are pivotal to the development of BCC $(3,12,13)$. Target genes in which expression is up-regulated directly by $\mathrm{HH}$ signaling are PTCH1, GLI family zinc finger 1 (GLI1), GLI2, protein kinase cAMP-activated catalytic subunit alpha (PRKACA) and hedgehog-interacting protein $(H H I P)(2,4,14)$. AKT serine/threonine kinase 1 ( $A K T 1)$, IGF binding protein 4 (IGFBP4), IGFBP2, secreted frizzled-related protein 2 (SFRP2), bone morphogenetic protein receptor type 2 (BMPR2), leucine-rich repeat containing $\mathrm{G}$ protein-coupled receptor 5 (GPR49) and platelet-derived growth factor receptor-alpha $(P D G F R \alpha)$ have been reported to be up- 
regulated in $\mathrm{BCC}(4,15,16)$. There is evidence that WNT activation is a downstream consequence of $\mathrm{HH}$ signaling in tumors $(17,18)$. Activation of the WNT pathway, typically caused by gene mutations, leads to increased transcription of genes related to growth, proliferation, differentiation, apoptosis, genetic stability, migration and angiogenesis $(17,19)$. It has also been reported that genes such as cyclin D2 (CCND2), calcium/calmodulin-dependent protein kinase II gamma (CAMK2G), casein kinase 2 alpha 2 (CSNK2A2), and frizzled receptors such as FZD7, FZD8 and FZD2 were deregulated in BCC (4). Larsimont et al. used a mouse model of BCC to show early expression of SRY sex-determining region Y-box 9 (SOX9) during tumorigenesis in a WNT- $\beta$ catenin-dependent manner. Deletion of SOX9 and constitutive activation of $\mathrm{HH}$ signaling prevents BCC development (20).

In the present study, the objectives were to focus on differential expression of genes belonging to the WNT and $\mathrm{HH}$ signaling pathways in patients with superficial and nodular BCC. Using quantitative real-time polymerase chain reaction (qPCR) array techniques and validation assay by qPCR, we identified alterations in the gene expression patterns of human nodular BCC.

\section{Materials and Methods}

Human tissue specimens. The first part of the present study involved the analysis of six BCC samples (three nodular and three superficial) and three healthy human epithelial tissue biopsies (normal skin), totaling nine distinct samples (Table I). Tissue biopsies were obtained from the Service of Dermatology at the Asa Norte Regional Hospital between 2011 and 2014 in Brazil. Normal tissue biopsies were collected from patients who underwent surgery for general dermatological purposes but not for neoplasm. The samples were collected and immediately transferred to RNA later ${ }^{\circledR}$ (Invitrogen, Life Technologies) and stored at $-80^{\circ} \mathrm{C}$ until required for analysis. BCC tumor types were confirmed by histopathological tests. The second part of the present study involved 48 samples of nodular BCC and 10 samples of healthy human skin, obtained from the same source. All pathologies (or lack thereof) were confirmed by histological examination. Samples with ambiguous histopathology were excluded. The study received approval from the Ethical Committee of the Catholic University of Brasilia (no. CEP/UCB 112/2009). The patients gave their written consent for use of their biopsy samples for this study.

RNA extraction and analysis and cDNA synthesis. Tissue disruption was carried out using a TissueLyser II (Qiagen, Hilden, Germany) with $5 \mathrm{~mm}$ steel beads, RNase-Free, $20 \mathrm{~Hz}, 3 \times 3 \mathrm{~min}$. Total RNA was isolated using the RNeasy Mini kit (Qiagen) according to the manufacturer's instructions. In order to evaluate the RNA integrity, $1 \mu \mathrm{l}$ of each sample was analyzed by gel electrophoresis. The RNA amount was quantified by Qubit ${ }^{\circledR}$ spectrophotometer (Thermo Fisher Scientific, Waltham, MA, USA). In addition, we used a Bioanalyzer 2100 (Agilent Technologies, Waldbronn, Germany) to ensure the quality of the samples. Genomic DNA contamination was ruled out using a gDNA random primer (Qiagen) for qPCR. $1 \mu \mathrm{g}$ of total RNA from each sample was used to synthetize cDNA using the $\mathrm{RT}^{2}$ First Strand kit (Qiagen) or the High Capacity cDNA
Table I. Clinical features of nine patients whose samples were used in the quantitative real-time polymerase chain reaction array.

\begin{tabular}{lcccc}
\hline $\begin{array}{l}\text { Sample } \\
\text { no. }\end{array}$ & Gender & $\begin{array}{c}\text { Age, } \\
\text { years }\end{array}$ & $\begin{array}{c}\text { Histological } \\
\text { type }\end{array}$ & $\begin{array}{c}\text { Anatomic } \\
\text { site }\end{array}$ \\
\hline 1 & Male & 85 & Nodular BCC & Chest \\
2 & Female & 97 & Nodular BCC & Face \\
3 & Female & 50 & Nodular BCC & Pinna \\
4 & Male & 50 & Superficial BCC & Lap \\
5 & Female & 47 & Superficial BCC & Pre-sternum \\
6 & Female & 94 & Superficial BCC & Nasal dorsum \\
7 & Male & 73 & Control tissue & Armpit \\
8 & Female & 53 & Control tissue & Armpit \\
9 & Female & 78 & Control tissue & Armpit \\
\hline
\end{tabular}

BCC: Basal cell carcinoma.

Reverse Transcription Kit (Thermo Fisher Scientific) according to the manufacturer's instructions. The RT ${ }^{2}$ RNA QC PCR Array (Qiagen) was used for quality control.

$q P C R$ array. In order to analyze the gene-expression profile, we used the Human Hedgehog Signaling RT ${ }^{2}$ Profiler $^{\mathrm{TM}}$ PCR Array version 3.0 (Qiagen) according to the manufacturer's instructions. This array contains 84 genes from the HH and WNT signaling pathways including genes involved in cell differentiation and multicellular organism development. Five housekeeping genes [beta-2microglobulin $(B 2 M)$, hypoxanthine phosphoribosyltransferase 1 (HPRT1), ribosomal protein L13a (RPL13A), glyceraldehyde-3phosphate dehydrogenase $(G A P D H)$, actin beta $(A C T B)]$ and controls were also included on each array for genomic DNA contamination detection, RNA quality, and general PCR performance. Genorm software (available at http:// medgen.ugent.be/ jvdesomp/genorm/), integrated by qbasePLUS software version 2.1 (Biogazelle NV, Zwijnaarde, Belgium) was used to identify the best housekeeping genes to analyze the gene expression profiles. qPCR array was carried out using Step One Plus (Thermo Fisher Scientific).

Validation assay by $q P C R$. The differential gene expression pattern was validated using qPCR with TaqMan ${ }^{\circledR}$ probes for 10 selected genes (casein kinase 1 delta (CSNK1D), PRKACA, protein kinase cAMP-activated catalytic subunit beta $(P R K A C B)$, protein kinase $\mathrm{X}$ linked $(P R K X)$, WNT inhibitory factor 1 (WIFI), WNT2B, WNT3, WNT10A, WNT1OB and WNT16) based on the expression pattern and the hierarchical cluster, $p$-value and fold-change values. $A C T B$ and $G A P D H$ genes were used as housekeeping genes for reference. We compared 48 samples of human nodular BCCs with 10 samples of healthy human epithelial tissue biopsies obtained in the same manner as mentioned above. Superficial BCC was not analyzed in this phase due to low sample availability compared to nodular BCC cases. qPCR assays followed the manufacturer's instructions in a 10 $\mu l$ reaction using Step One Plus (Thermo Fisher Scientific) equipment. The gene expression assays were approximately $100 \%$ efficient, with a slope value of - 3.32 and an r-value $>0.99$.

Data processing and cluster analysis. Gene-expression profiles were analyzed using Web-based PCR Array Data Analysis Software (Qiagen; http://pcrdataanalysis sabiosciences.com/pcr/arrayanalysis.php). 
Table II. Quantitative real-time polymerase chain reaction array gene expression profile results using cut-off of $p<0.05$. Genes are ranked according to expression change and those with more than 5-fold-change are shown in bold.

\begin{tabular}{|c|c|c|c|c|c|c|c|c|}
\hline \multicolumn{3}{|c|}{ Nodular BCC $v s$. normal skin } & \multicolumn{3}{|c|}{ Superficial BCC vs. normal skin } & \multicolumn{3}{|c|}{ Nodular vs. superficial BCC } \\
\hline Gene & $p$-Value & Fold change & Gene & $p$-Value & Fold change & Gene & $p$-Value & Fold change \\
\hline C6orf138 & $\mathbf{0 . 0 3}$ & 5.32 & WNT5A & 0.03 & 2.50 & WNT3 & 0.003 & -3.22 \\
\hline WNT5A & 0.04 & 3.82 & $N P C 1$ & 0.007 & -2.50 & WNT8A & 0.009 & -4.30 \\
\hline FKBP8 & 0.01 & -2.54 & PRKACA & 0.002 & -2.75 & WNT9B & 0.009 & -4.96 \\
\hline BMP8A & 0.04 & -2.63 & MTSS1 & 0.04 & -2.85 & WNT3A & 0.002 & -5.11 \\
\hline WNT5B & 0.01 & -2.93 & $F K B P 8$ & 0.009 & -3.26 & WNT7A & 0.009 & -7.14 \\
\hline NPC1 & 0.003 & -3.58 & MAPK1 & 0.02 & -3.39 & IHH & 0.002 & -7.55 \\
\hline WNT1 & 0.03 & -3.64 & $P R K A C G$ & 0.04 & -3.56 & CSNK1A1L & 0.008 & -9.87 \\
\hline$M A P K 1$ & 0.02 & -3.74 & $\mathrm{SHH}$ & 0.04 & -3.74 & PTCHD2 & 0.007 & -14.33 \\
\hline$P R K A C G$ & 0.04 & -3.81 & $W N T 2 B$ & 0.01 & -4.13 & DHH & 0.001 & -50.07 \\
\hline PRKACA & 0.002 & -3.84 & WNT16 & 0.03 & -4.23 & & & \\
\hline $\mathrm{SHH}$ & 0.02 & -4.48 & WNT10A & 0.01 & -5.41 & & & \\
\hline PTCHD1 & 0.006 & -4.62 & FGFR3 & 0.01 & -6.64 & & & \\
\hline$F G F R 3$ & 0.04 & -4.69 & WNT4 & 0.04 & -9.54 & & & \\
\hline WNTSA & 0.03 & -5.50 & WNT3 & 0.003 & -12.46 & & & \\
\hline$W N T 2 B$ & 0.01 & -7.94 & WNT1OB & 0.04 & -30.03 & & & \\
\hline WNT10B & 0.01 & -9.33 & $F G F 9$ & 0.03 & -30.06 & & & \\
\hline ВMP4 & 0.03 & -10.62 & WIF 1 & 0.003 & -45.58 & & & \\
\hline WIF1 & 0.001 & -11.40 & & & & & & \\
\hline WNT10A & 0.008 & -16.33 & & & & & & \\
\hline WNT4 & 0.03 & -25.17 & & & & & & \\
\hline WNT16 & 0.01 & -36.16 & & & & & & \\
\hline WNT3 & 0.002 & -40.18 & & & & & & \\
\hline
\end{tabular}

C18orf8: Chromosome 18 open reading frame 8; WNT5A: wingless-type MMTV integration site family, member 5A; WNT3: wingless-type MMTV integration site family, member 3; WNT16: wingless-type MMTV integration site family, member 16; WNT4: wingless-type MMTV integration site family, member 4; WNT10A: wingless-type MMTV integration site family, member 10A; WIF1: WNT inhibitory factor 1; BMP4: bone morphogenetic protein 4; WNT10B: wingless-type MMTV integration site family, member 10B; WNT2B: wingless-type MMTV integration site family, member 2B; WNT8A: wingless-type MMTV integration site family, member 8A; FGFR3: fibroblast growth factor receptor 3; PTCHD1: patched domain containing 1; SHH: sonic hedgehog; PRKACA: protein kinase cAMP-activated catalytic subunit alpha; $P R K A C G$ : protein kinase cAMP-activated catalytic subunit gamma; MAPK1: mitogen-activated protein kinase 1; WNT1: wingless-type MMTV integration site family, member 1; NPC1: NPC intracellular cholesterol transporter 1; WNT5B: wingless-type MMTV integration site family, member 5B; BMP8A: bone morphogenetic protein 8A; FKBP8: FK506 binding protein 8; FGF9: fibroblast growth factor 9; MTSS1: metastasis suppressor 1; PTCHD2: patched domain containing 2; CSNK1AIL: casein kinase 1 alpha 1 like; IHH: indian hedgehog; WNT7A: wingless-type MMTV integration site family, member 7A; WNT3A: wingless-type MMTV integration site family, member 3A; $D H H$ : desert hedgehog; WNT9A: wingless-type MMTV integration site family, member $9 \mathrm{~A}$.

\begin{abstract}
Student's $t$-test was used to compare average gene expressions between groups of samples. After normalization of the fold-change values, performed on Gene Cluster 3.0 software (21), unsupervised hierarchical clustering analysis was performed by the centroid linkage method. The k-means method was applied to organize genes and arrays. Similarity metric was based on Euclidean distance. Genes were then normalized and clustered using Cluster software (21) and visualized using Gene Tree View software (22). qPCR data analysis used qBasePlus software version 2.1 (Biogazelle NV, Zwijnaarde, Belgium) to acquire the relative expression of the target genes in the 48 nodular BCC samples compared to controls.
\end{abstract}

\section{Results}

Several lines of evidence implicate cross-talk between the WNT and HH pathways in tumorigenesis and suggest their involvement in progression to aggressive, invasive, and metastatic disease stages $(3,16,23,24)$. Scant data have been published regarding gene involvement in either nodular or superficial BCC tumors and no extensive analysis of gene expression modulation exists $(3,4,13,25)$.

In the current study, six BCC specimens were analyzed by qPCR array to investigate gene expression profiles. Nodular and superficial BCC samples were obtained upon excision of primary skin tumors. The results obtained demonstrated modulation of several genes belonging to the WNT and $\mathrm{HH}$ pathways (Table II). From the initial gene-expression analysis, we observed 30 genes with differential expression in three comparisons: nodular BCC compared to normal skin, superficial BCC compared to normal skin and nodular BCC compared to superficial BCC. In nodular BCC, 22 differentially regulated genes $(p<0.05$; fold change cut-off 
$>2.5)$. Only patched domain containing 4 (C6ORF138) and $W N T 5 A$ were up-regulated whereas the other 20 genes were down-regulated in nodular BCC compared with normal skin. Compared with normal skin 17 genes were differentially regulated in superficial BCC. Nine genes were downregulated in superficial compared with nodular BCC. In all groups, several genes belonging to the WNT family were down-regulated in both nodular and superficial BCC samples compared to normal skin (Table II).

Hierarchical clustering of $H H$ and WNT pathway genes in $B C C$. In order to select the genes for validation in a higher number of nodular BCC samples $(n=48)$, we performed hierarchical clustering analysis of the dataset from the previous analyses. Figure 1 shows the clustering dendrogram identifying the main outcomes. It lists 63 genes with correlation higher than 0.90 . Normal skin specimens formed a distinct cluster relative to the six BCC samples. Nodular BCC samples presented a different gene-regulation profile in relation to normal skin tissue, with relative similarities to superficial BCC. Nodular BCC presented up-regulation of $C S N K 1 D$, RAS-associated protein $R A B 23, P R K A C B, P R K X$, $W N T 5 A$, bone morphogenetic protein 6 (BMP6), F-box and WD repeat domain containing 11 ( $F B X W 11)$, intraflagellar transport 52 (IFT52), and siah E3 ubiquitin protein ligase 1 (SIAH1); and down-regulation of PRKACA, WIF1, WNT2B, WNT3, WNT10A, WNT10B, WNT16, FK506 binding protein 8 (FKBP8), NPC intracellular cholesterol transporter 1 (NPC1), and mitogen-activated protein kinase 1 (MAPK1).

Since the WNT pathway is poorly studied in skin cancer, we decided to focus on WNT pathway genes that were highlighted in the clustering analysis. In order to reinforce the differential expression pattern in a population of nodular BCC, we performed an extended qPCR assay using tumor samples from 48 patients for analysis of 10 selected genes. The secondary qPCR analysis focused on the following genes: CSNK1D, PRKACA, PRKACB, PRKX, WIF1, WNT2B, WNT3, WNT10A, WNT10B and WNT16. WNT5A was not selected since it has been extensively studied and our data from the first experimental phase corroborated its up-regulation in nodular BCC, as described previously (26, 27). The second experimental phase confirmed $P R K X$ as being up-regulated $(p=0.01016)$, and WNT3 and WNT16 as being down-regulated $(p=0.000081$ and $p=0.0117$, respectively) in nodular BCC. The expression profiles of the remaining seven genes did not significantly differ.

\section{Discussion}

$\mathrm{BCC}$ is a cutaneous malignant tumor that is locally invasive and has the highest incidence in Caucasian individuals, but rarely causes metastasis or death $(5,8,9)$. Active $\mathrm{HH}$ signaling is implicated in BCC malignancy $(3,24)$. WNT

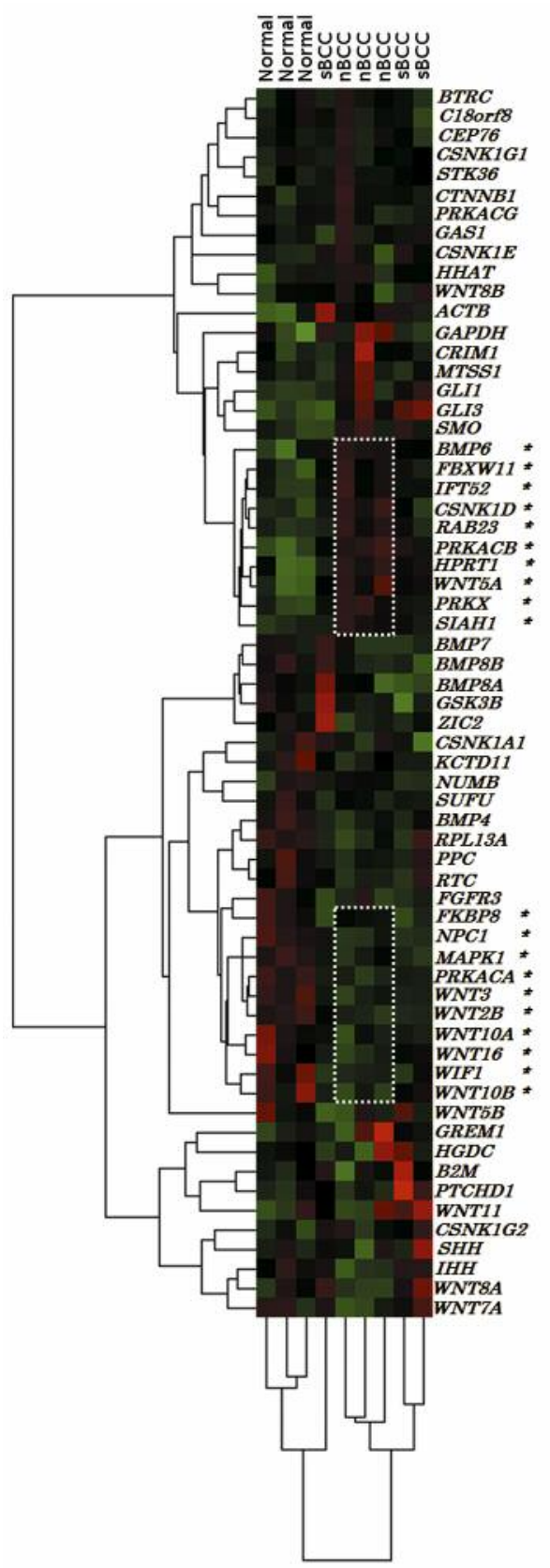

Figure 1. Hierarchical clustering of the gene expression from nine samples analyzed in quantitative real-time polymerase chain reaction array. Data from normal skin tissue (normal), superficial BCC ( $s B C C$ ) and nodular $B C C(n B C C)$ were clustered by centroid linkage method. Nodular BCC showed the greatest heterogeneity. Genes up-regulated and down-regulated in the nodular BCC profile are highlighted (*). Figure was generated by GIMP 2.8.16 GNU - Image Manipulation Program and Adobe Photoshop.

family genes are implicated in many cell processes such as cell proliferation, cell fate, polarity, differentiation and migration $(18,19)$. To date, more than 19 human WNT genes have bene identified and many of them have different 
isoforms (28). Hierarchical clustering analysis of our dataset showed nodular BCC specimens clustered together and had a different gene modulation in relation to normal skin, relatively similar to superficial $\mathrm{BCC}$, in agreement with $\mathrm{Yu}$ et al. (4).

Our study focused on nodular BCC and confirmed upregulation of $P R K X$, whereas $W N T 3$ and WNT16 were downregulated. Human PRKX is a type-I cAMP-dependent protein kinase and is associated with the WNT pathway (29). There is evidence that PRKX stimulates endothelial cell proliferation, migration, and vascular-like structure formation in multiple developing tissue processes related to modulation of angiogenesis $(29,30)$. Studies report that PRKX binds to peptidylprolyl cis/trans isomerase, NIMA-interacting 1 (PIN1), membrane-associated guanylate kinase, WW and PDZ domain containing 1 (MAGI1) and BCL2-associated athanogene 3 (BAG3), which have been implicated in a variety of cellular functions, including proliferation, apoptosis, development, differentiation and tumorigenesis $(29,31,32)$. We report for the first time that the $P R K X$ gene is up-regulated in nodular BCC. Since nodular BCC has a more aggressive phenotype than superficial BCC, it is reasonable to expect that the up-regulation observed for PRKX could be related to neoplastic transformation due to stimulation of angiogenesis. Newell et al. showed that BCC exhibited a 5-fold increase in angiogenesis compared to normal skin (33).

WNT3 belongs to the WNT1 class of ligands, which stimulate the canonical WNT/ $\beta$-catenin pathway by binding to a Frizzled receptor (34). There is evidence that WNT3 also acts through a non-canonical WNT signaling pathway that involves phosphorylation of mitogen-activated protein kinases (MAPKs), the Ras-dependent extracellular-signalregulated kinases 1/2/5 (ERK1/2/5) (35). WNT3 overexpression is implicated in tumor proliferation, inhibition of tumor apoptosis, poor prognosis and promotion of malignant transformation in cancer such as human hepatocellular carcinoma, non-small cell lung cancer, and squamous cell carcinoma of the oral cavity (34-38). It is expressed in the NT2, MCF-7 and MKN45 cell lines (39). In addition, Kimura et al. presented the hypothesis that WNT3 signaling is required for increased mantle cell lymphoma lymphomagenesis demonstrated in hematological malignancies (40). The literature suggests that WNT3 overexpression is associated with the development of aggressive malignancy during tumor progression. We studied nodular BCC, which is not a very aggressive tumor compared to those mentioned above. Our results suggested that nodular BCC exhibits a different gene expression profile from very aggressive human tumors, which would be compatible with down-regulation of WNT3 in nodular BCC.

The other differentially regulated gene was WNT16, which is involved in oncogenesis and in several developmental processes, including regulation of cell fate and patterning during embryogenesis $(41,42)$. WNT16 expression is found in spleen, appendix, lymph nodes, and bone marrow of patients with pre-B acute lymphoblastoid leukemia with a $\mathrm{t}(1 ; 19)$ chromosomal translocation, and is implicated in lineage specification in B-cell development (43). Fear et al. identified alternative WNT16 isoforms A and B (41). The isoforms showed differential expression in adult human tissues. Teh et al. reported WNT16B but not WNT16A isoform as being up-regulated in BCC compared with normal skin (42). Nonetheless, the up-regulation seen by Teh et al. was analyzed using only three human BCC samples. In the current study, we analyzed 48 samples of nodular BCC, although the data do not differentiate between WNT16 isoforms.

In conclusion, functional studies will be needed in order to confirm the role of PRKX, WNT3 and WNT16 in nodular BCC. The gene-expression profiles obtained here give us a starting point for understanding the molecular basis of nodular BCC. Hierarchical clustering showed distinct profiles for the samples, suggesting a strong influence of the WNT pathway in nodular BCC. Taken together, our findings suggest that WNT3, WNT16 and PRKX are involved in the modulation of WNT signaling, possibly leading to an imbalance in growth, proliferation and differentiation. It will be important to investigate whether skin cancer subtypes exhibit distinct geneexpression profiles associated with WNT signaling leading to aggressive skin tumor, as compared to superficial BCC. It is tempting to speculate that WNT signaling may have an important role in differentiation of epithelial tissues. The modulation of genes belonging to the WNT pathway may contribute to the dysregulation of nodular BCC differentiation as observed in skin cancer subtypes.

\section{Acknowledgements}

The Authors are grateful to patients and their families for authorizing the molecular assays of their tumor biopsies and normal skin biopsies in Asa Norte Regional Hospital (HRAN). We thank the dermatological staff from the Service of Dermatology from HRAN for all their help. Rosângela Vieira de Andrade Ph.D. had full access to all of the data in the study and takes responsibility for the integrity of the data and the accuracy of the data analysis.

\section{References}

1 Bonilla X, Parmentier L, King B, Bezrukov F, Kaya G, Zoete V, Seplyarskiy VB, Sharpe HJ, McKee T, Letourneau A, Ribaux PG, Popadin K, Basset-Seguin N, Ben Chaabene R, Santoni FA, Andrianova MA, Guipponi M, Garieri M, Verdan C, Grosdemange K, Sumara O, Eilers M, Aifantis I, Michielin O, de Sauvage FJ, Antonarakis SE and Nikolaev SI: Genomic analysis identifies new drivers and progression pathways in skin basal cell carcinoma. Nat Genet 48: 398-406, 2016.

2 Epstein EH: Basal cell carcinomas: attack of the hedgehog. Nat Rev Cancer 8: 743-754, 2008. 
3 Jee BA, Lim H, Kwon SM, Jo Y, Park MC, Lee IJ and Woo HG Molecular classification of basal cell carcinoma of skin by gene expression profiling. Mol Carcinog 54: 1605-1612, 2014.

4 Yu M, Zloty D, Cowan B, Shapiro J, Haegert A, Bell RH, Warshawski L, Carr N and McElwee KJ: Superficial, nodular, and morpheiform basal-cell carcinomas exhibit distinct gene expression profiles. J Invest Dermatol 128: 1797-1805, 2008.

5 Martinez MAR, Francisco G, Cabral LS, Ruiz IRG and Neto CF: Genética molecular aplicada ao câncer cutâneo não melanoma. An Bras Dermatol 81: 405-419, 2006.

6 Rippey JJ: Why classify basal cell carcinomas? Histopathology 32: 393-398, 1998.

7 Sexton M, Jones DB and Maloney ME: Histologic pattern analysis of basal cell carcinoma. Study of a series of 1039 consecutive neoplasms. J Am Acad Dermatol 23: 1118-1126, 1990.

8 Dubas LE and Ingraffea A: Nonmelanoma skin cancer. Facial Plast Surg Clin North Am 21: 43-53, 2013.

9 Chinem VP and Miot HA: Epidemiologia do carcinoma basocelular. An Bras Dermatol 86: 292-305, 2011.

10 Santos I, De Mello RJV, Dos Santos IB and Dos Santos RA: Estudo quantitativo das células de Langerhans em carcinomas basocelulares com maior e menor potencial de agressividade local. An Bras Dermatol 85: 165-171, 2010.

11 Celebi AR, Kiratli H and Soylemezoglu F: Evaluation of the 'Hedgehog' signaling pathways in squamous and basal cell carcinomas of the eyelids and conjunctiva. Oncol Lett 12: 467472, 2016.

12 Daya-Grosjean L and Couvé-Privat S: Sonic hedgehog signaling in basal cell carcinomas. Cancer Lett 225: 181-192, 2005.

13 Tanese K, Fukuma M, Yamada T, Mori T, Yoshikawa T, Watanabe W, Ishiko A, Amagai M, Nishikawa T and Sakamoto M: G Protein-coupled receptor GPR49 is up-regulated in basal cell carcinoma and promotes cell proliferation and tumor formation. Am J Pathol 173: 835-843, 2008.

14 Howell BG, Solish N, Lu C, Watanabe H, Mamelak AJ, Freed I, Wang B and Sauder DN: Microarray profiles of human basal cell carcinoma: Insights into tumor growth and behavior. J Dermatol Sci 39: 39-51, 2005.

15 Athar M, Tang X, Lee JL, Kopelovich L and Kim AL: Hedgehog signalling in skin development and cancer. Exp Dermatol 15: 667-677, 2006.

16 Iwasaki JK, Srivastava D, Moy RL, Lin HJ and Kouba DJ: The molecular genetics underlying basal cell carcinoma pathogenesis and links to targeted therapeutics. J Am Acad Dermatol 66: e167-78, 2012.

17 Brinkhuizen T, van den Hurk K, Winnepenninckx VJL, de Hoon JP, van Marion AM, Veeck J, Manon van Engeland M and van Steensel MAM: Epigenetic changes in basal cell carcinoma affect SHH and WNT signaling components. PLoS ONE 7: e51710, 2012.

18 Lustig B and Behrens J: The WNT signaling pathway and its role in tumor development. J Cancer Res Clin Oncol 129: 199221,2003

19 Anastas JN and Moon RT: WNT signalling pathways as therapeutic targets in cancer. Nat Rev Cancer 13: 11-26, 2013.

20 Larsimont JC, Youssef KK, Sánchez-Danés A, Sukumaran V, Defrance M, Delatte B, Liagre M, Baatsen P, Marine JC, Lippens S, Guerin C, Del Marmol V, Vanderwinden JM, Fuks F and Blanpain C: SOX9 controls self-renewal of oncogene targeted cells and links tumor initiation and invasion. Cell Stem Cell 17: 60-73, 2015.
21 de Hoon MJL, Imoto S, Nolan J and Miyano S: Open source clustering software. Bioinformatics 20: 1453-1454, 2004.

22 Saldanha AJ: Java Treeview - extensible visualization of microarray data. Bioinformatics 20: 3246-3248, 2004.

23 Mimeault $M$ and Batra SK: Frequent deregulations in the hedgehog signaling network and cross-talks with the epidermal growth factor receptor pathway involved in cancer progression and targeted therapies. Pharmacol Rev 62: 497-524, 2010.

24 Taipale $\mathrm{J}$ and Beachy P: The Hedgehog and WNT signalling pathways in cancer. Nature 411: 349-354, 2001.

25 O'Driscoll L, McMorrow J, Doolan P, McKiernan E, Mehta JP, Ryan E, Gammell P, Joyce H, O'Donovan N, Walsh N and Clynes M: Investigation of the molecular profile of basal cell carcinoma using whole genome microarrays. Mol Cancer 5: 74, 2006.

26 Kang MI, Baker AR, Dextras CR, Cabarcas SM, Young MR and Colburn NH: Targeting of noncanonical WNT5A signaling by AP-1 blocker dominant-negative JUN when it inhibits skin carcinogenesis. Genes Cancer 3: 37-50, 2012.

27 Pourreyron C, Reilly L, Proby C, Panteleyev A, Fleming C, McLean K, South AP and Foerster J: WNT5A is strongly expressed at the leading edge in non-melanoma skin cancer, forming active gradients, while canonical WNT signalling is repressed. PLoS One 7: e31827, 2012.

28 Koch A, Waha A, Hartmann W, Hrychyk A, Schüller U, Waha A, Wharton KA, Fuchs SY, Von Schweinitz D and Pietsch T: Elevated expression of WNT antagonists is a common event in hepatoblastomas. Clin Cancer Res 11: 4295-4304, 2005.

29 Li X, Iomini C, Hyink D and Wilson PD: PRKX critically regulates endothelial cell proliferation, migration, and vascularlike structure formation. Dev Biol 356: 475-485, 2011.

30 Huang S, Alberts I, Li Q and Li X: PRKX, a novel cAMPdependent protein kinase member, plays an important role in development. J Cell Biochem 117: 566-573, 2016.

31 Lu KP: Pinning down cell signaling, cancer and Alzheimer's disease. Trends Biochem Sci 29: 200-209, 2004.

32 Wulf G, Garg P, Liou YC, Iglehart D and Lu KP: Modeling breast cancer in vivo and ex vivo reveals an essential role of PIN1 in tumorigenesis. EMBO J 23: 3397-3407, 2004.

33 Newell B, Bedlow AJ, Cliff S, Drysdale SB, Stanton AWB and Mortimer PS: Comparison of the microvasculature of basal cell carcinoma and actinic keratosis using intravital microscopy and immunohistochemistry. Br J Dermatol 149: 105-110, 2003.

$34 \mathrm{Kim}$ M, Lee HC, Tsedensodnom O, Hartley R, Lim YS, Yu E, Merle P and Wands JR: Functional interaction between WNT3 and FRIZZLED-7 leads to activation of the WNT/ $\beta$-catenin signaling pathway in hepatocellular carcinoma cells. J Hepatol 48: 780-791, 2008.

35 Nambotin SB, Tomimaru Y, Merle P, Wands JR and Kim M: Functional consequences of WNT3/FRIZZLED-7-mediated signaling in non-transformed hepatic cells. Oncogenesis 1: e31, 2012.

36 Andrade Filho PA, Letra A, Cramer A, Prasad JL, Garlet GP, Vieira AR, Ferris RL and Menezes R: Insights from studies with oral cleft genes suggest associations between WNT-pathway genes and risk of oral cancer. J Dent Res 90: 740-746, 2011.

37 Uraguchi M, Morikawa M, Shirakawa M, Sanada K and Imai $\mathrm{K}$ : Activation of WNT family expression and signaling in squamous cell carcinomas of the oral cavity. J Dent Res 83: 327-332, 2004 
38 Voloshanenko O, Erdmann G, Dubash TD, Augustin I, Metzig M, Moffa G, Hundsrucker C, Kerr G, Sandmann T, Anchang B, Demir K, Boehm C, Leible S, Ball CR, Glimm H, Spang R and Boutros M: WNT secretion is required to maintain high levels of WNT activity in colon cancer cells. Nat Commun 4: 2610, 2013.

39 Katoh M: Regulation of WNT3 and WNT3A mRNAs in human cancer cell lines NT2, MCF-7, and MKN45. Int J Oncol 20: 373377, 2002.

40 Kimura Y, Arakawa F, Kiyasu J, Miyoshi H, Yoshida M, Ichikawa A, Niino D, Sugita Y, Okamura T, Doi A, Yasuda K, Tashiro K, Kuhara S and Ohshima K: The WNT signaling pathway and mitotic regulators in the initiation and evolution of mantle cell lymphoma: Gene-expression analysis. Int J Oncol 43: 457-468, 2013.

41 Fear MW, Kelsell DP, Spurr NK and Barnes MR: WNT-16a, a novel WNT-16 isoform, which shows differential expression in adult human tissues. Biochem Biophys Res Commun 278: 814820,2000
42 Teh MT, Blaydon D, Ghali LR, Briggs V, Edmunds S, Pantazi E, Barnes MR, Leigh IM, Kelsell DP and Philpott MP: Role for WNT16B in human epidermal keratinocyte proliferation and differentiation. J Cell Sci 120: 330-339, 2007.

43 McWhirter JR, Neuteboom STC, Wancewicz EV, Monia BP, Downing JR, Murre C. Oncogenic homeodomain transcription factor E2A-PBX1 activates a novel WNT gene in pre-B acute lymphoblastoid leukemia. Proc Natl Acad Sci USA 96: 1146411469, 1999.
Received July 20, 2016

Revised August 15, 2016

Accepted August 18, 2016 